\title{
ALIMENTOS EM FAVOR DE EX-CÔNJUGE OU COMPANHEIRA: REFLEXÕES SOBRE A (DES)IGUALDADE DE GENERO A PARTIR DA JURISPRUDENCIA DO STJ
}

\author{
Ana Carla Harmatiuk Matos ${ }^{1}$ \\ Anderson Pressendo Mendes ${ }^{2}$ \\ Andressa Regina Bissolotti dos Santos ${ }^{3}$ \\ Ligia Ziggiotti de Oliveira ${ }^{4}$ \\ Micheli Mayumi Iwasaki ${ }^{5}$
}

\section{Resumo}

O presente artigo tem por escopo investigar a condição feminina no Judiciário, notadamente no Superior Tribunal de Justiça, a partir da abordagem crítico-analítica da jurisprudência desta Corte Superior em matéria de alimentos arbitrados em favor de ex-cônjuge mulher ou companheira. Intenta-se perquirir a ratio decidendi de decisões proferidas no período compreendido entre o último biênio da década de 1980 até os dias atuais, buscando-se elucidar os argumentos, explícitos ou implícitos, presentes ou ausentes nestes julgados, e sua projeção na representação da mulher na sociedade brasileira. Identifica-se uma forte inclinação desta Corte em limitar, temporal e quantitativamente, a pensão alimentícia em favor da mulher, descurando, em regra, de sua vulnerabilidade socioeconômica, cuja origem remonta à desigualdade de gênero no seio familiar. Cogita-se, ainda, dos chamados alimentos compensatórios como possível consequência da desvalorização da categoria jurídica alimentar. Conclui-se que a representação da mulher na sociedade brasileira caracteriza-se pelo preconceito, que se projeta, inclusive, para o Judiciário.

\footnotetext{
${ }^{1}$ Doutora pela Universidade Federal do Paraná. Tuttora Diritto na Universidade di Pisa-Italia. Professora na graduação, mestrado e doutorado em Direito da Universidade Federal do Paraná. Vice-Coordenadora do Programa da Pós-graduação em Direito da Universidade Federal do Paraná. Coordenadora do Eixo de Relações Jurídicas Familiares e Sucessões, do Núcleo de Estudos em Direito Civil-Constitucional - Projeto Virada de Copénico, vinculado ao Programa de Pós-Graduação em Direito da Universidade Federal do Paraná. E-mail: a.c.matos@uol.com.br

${ }^{2}$ Mestrando em Direito das Relações Sociais pelo Programa de Pós-Graduação da Universidade Federal do Paraná. Membro do Núcleo de Estudos em Direio Civil Constitucional - Projeto Virada de Copérnico, vinculado ao Programa de Pós-Graduação em Direito da Universidade Federal do Paraná. E-mail: pressendo.ufpr@gmail.com

${ }^{3}$ Pesquisadora bolsista pela CAPES, mestranda em Direitos Humanos e Democracia pelo Programa de Pós-Graduação da Universidade Federal do Paraná. Membra do Núcleo de Estudos em Direito Civil Constitucional - Projeto Virada de Copérnico, vinculado ao Programa de Pós-Graduação em Direito da Universidade Federal do Paraná. E-mail: bissolottiandressa@gmail.com

${ }^{4}$ Doutoranda em Direitos Humanos e Democracia pelo Programa de Pós-Graduação da Universidade Federal do Paraná. Professora da graduação em Direito do Centro Universitário Autônomo do Brasil. Pesquisadora visitante do Instituto Max-Planck de Direito Comparado e Direito Internacional Privado em Hamburgo, na Alemanha. Membra do Núcleo de Estudos em Direito Civil-Constitucional - Projeto Virada de Copérnico, vinculado ao Programa de Pós-Graduação em Direito da Universidade Federal do Paraná. E-mail: ziggiotti@gmail.com

${ }^{5}$ Mestra em Direito pela Universidade Federal do Paraná e especialista em Sociologia Política pela Universidade Federal do Paraná. Membra do Núcleo de Estudos de Direito Civil Constitucional - Projeto de Pesquisa Virada de Copérnico, vinculado ao Programa de Pós-Graduação em Direito da Universidade Federal do Paraná. E-mail: michelimayumi@gmail.com
} vol. 08, nº. 04, Número Especial. Rio de Janeiro, 2015.pp. 2474-2492 
Palavras-Chave: Condição feminina. Desigualdade de gênero. Superior Tribunal de Justiça. Desvalorização dos alimentos. Alimentos compensatórios.

\section{INTRODUÇÃO}

Em fórum virtual, certo internauta questiona por que as mulheres aplicam, em relacionamentos íntimos, o "golpe da pensão". Dentre os comentários, são relembrados os casos midiáticos nos quais, conforme se noticiou, angariaram as ditas "golpistas" vultuosos valores às custas dos ex-maridos.

Este recorte sobre aquelas que, nos processos de família, buscam a segurança alimentar em face daqueles com quem se relacionaram conjugalmente não parece descolado do imaginário prevalente. Com efeito, o senso comum (BOURDIEU, 1989) ${ }^{6}$ ainda parece agregar ao feminino certa inclinação à astúcia no tocante ao patrimônio dos companheiros (HESPANHA, 2010)7. Escolhas legislativas como a imposição do regime de separação de bens quando um dos nubentes tem mais de 70 anos - sob o argumento de se evitarem, assim, casamentos interesseiros -, possibilitam similar reflexão.

No que diz respeito aos alimentos, a impressão parece decorrer, primeiramente, da predominância das mulheres, em comparação aos homens, em polo ativo desta sorte de demanda. Trata-se, pois, de um dos muitos casos em direito das famílias que atesta a neutralidade da norma escrita, do ponto de vista de gênero, mas que recebe contornos bastante claros e sugestivos na realidade vivida (DICUCK, 2006).

Nesse sentido, exige reflexão o abismo entre quem paga e quem recebe alimentos, bem como se esta questão se relaciona com as distâncias entre as possibilidades de crescimento individual e econômico que têm, efetivamente, homens e mulheres no país. O comprometimento que assumem no quadrante doméstico é igualmente desequilibrado, o que mitiga e expande, por influência de critérios sexuais e de gênero, as desejáveis vias de independência financeira do grupo familiar.

Em síntese, e conforme atestam os mais variados dados - alguns revisitados, à guisa de problematização, ao longo do texto -, vislumbra-se a igualdade, no país, ainda como uma promessa distante das mais corriqueiras dinâmicas familiares.

\footnotetext{
${ }^{6}$ Senso comum que manifesta "uma espécie de sentido do jogo que não tem necessidade de raciocinar para se orientar e se situar de maneira racional num espaço [e num campo próprio de racionalidade]” BOURDIEU, Pierre. O poder simbólico. Lisboa: Difel, 1989, p. 62. A ideia advém da ideia de habitus, que o autor indica como "um conhecimento adquirido e também um haver, um capital (de um sujeito transcendental na tradição idealista), o habitus, a hexis, indica uma disposição incorporada, quase postural". Ibidem, p. 61.

${ }^{7}$ Neste sentido, António Manuel HESPANHA identifica, nas sociedades de Antigo Regime, e mesmo antes, forte conexão entre o feminino e a indignidade, a fragilidade, a passividade e a perversidade (HESPANHA, António Manuel. Imbecillitas: as bemaventuranças da inferioridade nas sociedades de Antigo Regime. São Paulo: Annablume, 2010, p. 68-76). Conforme sugere o autor, estas imagens podem não ter sido suficientemente apagadas pelo tempo.
} 
Referidas nuances, contudo, como bem evidencia o senso comum ilustrado ao início, não costumam colorir a análise de alimentos a ex-cônjuge ou companheira, personagens sobre as quais parece ainda persistir certa ordem de desconfiança a inspirar redobrada vigília.

A compreensão dos juristas a este propósito, por sua vez, embora especializada, não se afasta da conjuntura social em que se insere. Por isso, a jurisprudência (FACHIN, 2014) ${ }^{8}$ fornece relevante fonte de análise acerca do tema. Se o irrisório acesso à Justiça não permite que dos julgados se extraiam conclusões definitivas acerca do contexto circundante, as decisões oferecem, indubitavelmente, um dos pontos mais visíveis da prática cotidiana do direito, e constituem relevante elo da cadeia de produção e reprodução de narrativas sobre os papeis sexuais na contemporaneidade (GASTRON, 2013).

O seguinte método de análise de fundamentação das decisões selecionadas leva em consideração que são tais discursos institucionais produzidos por sujeitos, e que, portanto, revelam relações de poder que envolvem suas atuações e as de suas instituições (OLIVEIRA, 2007).

Neste sentido, o entendimento do Superior Tribunal de Justiça - identificado, a partir de então, simplesmente como STJ - acerca dos alimentos pagos à ex-consorte permite questionar o impacto do senso comum que insiste em identificar tal obrigação como uma espécie de "aposentadoria" às credoras, que se valeriam do instrumento para alçar a cômoda condição de enriquecimento às penas daqueles com quem conviveram. Por tal motivo, parecem emergir parâmetros bastante restritivos com o objetivo de se obstarem supostos parasitismos. A este respeito versa, pois, o presente estudo.

Para impulsionar o propósito, o limite temporal selecionado coincide com a "Virada de Copérnico" de 1988, protagonizada pela Constituição da República. Destarte, concentrou-se a pesquisa do último biênio da década de 1980 ao presente. Constituiu a principal fonte de buscas o acervo jurisprudencial eletrônico do STJ, o qual se acessou, especialmente, a partir das seguintes: palavras-chave: "alimentos pensão ex-cônjuge" e "pensão alimentícia ex-cônjuge".

O encaminhamento permitiu a estruturação objetiva do sentido das decisões de referida Corte acerca do tema, bem como a problematização, do ponto de vista de gênero", quanto aos seus mais constantes posicionamentos. E, ainda, conduziu à hipótese de que os chamados alimentos compensatórios podem se diagnosticar como provável efeito da crescente desvalorização do instituto da pensão a ex-cônjuge na experiência decisória atual.

\footnotetext{
${ }^{8}$ Emprega-se o termo, ainda que conhecidos seus limites. Nos dizeres de Luiz Edson Fachin, quanto ao cenário pátrio, "falta solidez hermenêutica no conjunto dos precedentes dos tribunais que deveriam trazer estabilidade e previsibilidade, que são próprias do verdadeiro sentido da jurisprudência" (FACHIN, Luiz Edson. Um país sem jurisprudência. Revista IBDFAM, Edição 11, Maio 2014, p. 5).

9 A categoria "gênero" diz respeito aos valores que se relacionam às diferenças sexuais durante o processo de socialização. vol. 08, nº. 04, Número Especial. Rio de Janeiro, 2015. pp. 2474-2492 


\section{A RATIO DECIDENDI NO SUPERIOR TRIBUNAL DE JUSTIÇA}

Da análise dos julgados que tratam da matéria de obrigação alimentar em favor de ex-esposas e companheiras, é possível identificar um rol de condicionantes e limites que impõem às mulheres um forte juízo de valores a partir de percepções ou preconceitos que parecem cada vez mais idealizados frente às suas realidades concretas.

Em recente notícia publicada pelo STJ, intitulada "Quarta Turma dispensa ex-companheiro de pagar alimentos definitivos" ${ }^{\prime 10}$, há uma síntese da sua jurisprudência nessa matéria.

Nesse caso, o STJ decidiu pela conversão dos alimentos definitivos em transitórios pelo prazo de 2 anos. A mulher dedicou-se exclusivamente à educação dos filhos e viveu em união estável por 16 anos, até 2007, quando já contava com 55 anos de idade. Inicialmente, em seu favor, foram fixados alimentos no valor de 4 salários mínimos, objeto de exoneração em 2010 sob o fundamento de que ela gozaria de boas condições de saúde, possuiria curso superior e teria, portanto, a possibilidade de ingresso no mercado de trabalho para prover seu próprio sustento. A apelação reformou a sentença para reestabelecer os alimentos definitivos em 4 salários mínimos, também por considerar o padrão de vida ostentado por mais de uma década e a impossibilidade de reinserção imediata em atividade laboral. E para explicar a excepcionalidade da obrigação alimentar em favor de ex-mulher conclui a notícia:

No recurso especial, o ex-companheiro alegou que "somente a incapacidade laboral permanente justifica a fixação de alimentos sem termo final" e que "mesmo que sejam fixados excepcionalmente sem termo certo, uma vez assegurado ao alimentado tempo hábil para se inserir no mercado de trabalho, é possível a cessação da pensão pelo decurso do lapso temporal razoável, sem necessidade de alteração do binômio necessidade-possibilidade".

O relator, ministro Luis Felipe Salomão, acolheu o argumento de que não há necessidade permanente de sustento. Ele destacou que a obrigação de pensão alimentar para ex-cônjuges vem sendo considerada uma excepcionalidade, incidente apenas "nas hipóteses em que o exparceiro alimentado não dispõe de reais condições de readquirir sua autonomia financeira". Ao levar em consideração as particularidades do caso - tempo da separação, cerca de seis anos de pagamento da pensão, capacidade física, mental e técnica (formação em ensino superior e um trabalho de confecção de bolos e doces caseiros mencionado nos autos) -, Salomão decidiu estabelecer prazo de dois anos para a exoneração definitiva dos alimentos. O prazo é adequado, segundo o ministro, para que ela "procure, enfim, inserir-se no mercado de trabalho de modo a subsidiar seu próprio sustento.".1

O resumo do entendimento já consolidado no STJ nessa matéria, a partir do caso concreto narrado, permite compreender a ratio decidendi que permeia a sua jurisprudência. Alguns elementos são bastante frequentes e aparecem de forma isolada ou cumulada nas decisões.

\section{A presunção da igualdade de gênero}

\footnotetext{
10 Disponível em: <http://www.stj.jus.br/sites/STJ/default/pt_BR/noticias/noticias/Quarta-Turma-dispensaex\%E2\%80\%93companheiro-de-pagar-alimentos-definitivos $>$. Acesso em 23.05.2015.

${ }^{11}$ Idem.
} 
Argumento bastante invocado nos acórdãos do STJ está relacionado a uma presunção de igualdade (material) a partir do ingresso da mulher ao mercado de trabalho e que afasta a incidência da obrigação alimentar em seu favor. Um caso exemplificativo é do REsp 21,697/SP, julgado em 1993, em cuja ementa consta: "Hodiernamente, dada a equiparação profissional entre mulheres e homens, ambos disputando em condições de igualdade o mercado de trabalho, não se mostram devidos, [...] alimentos aos ex-cônjuges, salvo se comprovada a incapacidade laborativa de um deles". ${ }^{12}$

Em que pese o STJ adote essa fundamentação da igualdade de gênero há mais de duas décadas, da pesquisa jurisprudencial realizada, não foi encontrado nenhum precedente em que os alimentos fossem requeridos pelo ex-marido à mulher.

\section{Alimentos temporários como regra}

Outro fundamento reiterado com frequência na jurisprudência do STJ é a de que os alimentos fixados em favor de ex-cônjuge ou companheira são de natureza transitória, limitados a dois anos, que seria tempo suficiente à reinserção no mercado de trabalho para prover o seu autossustento.

Assim, a obrigação alimentar em favor de ex-cônjuge não se funda no binômio necessidade e possibilidade, mas no exercício de futurologia em que há certeza de que o prazo bienal é bastante para que qualquer mulher saudável estabeleça sua independência financeira. ${ }^{13}$ Aquele caso concreto noticiado pela imprensa do STJ é exemplo desse parâmetro: atualmente com 63 anos de idade, a ex-companheira terá alimentos temporários por mais dois anos, quando deverá estar inserida no mercado de trabalho tal qual o alimentante.

\section{Alimentos não podem incentivar ao ócio}

\footnotetext{
${ }^{12}$ REsp 21.697/SP, Rel. Ministro SÁLVIO DE FIGUEIREDO TEIXEIRA, QUARTA TURMA, julgado em 14/06/1993, DJ 27/09/1993, p. 19823.

13 CIVIL. FAMÍlIA. RECURSO ESPECIAL. FAMÍLIA. PENSÃO ALIMENTÍCIA. AÇÃO REVISIONAL E EXONERATÓRIA DE ALIMENTOS. [...] EXONERATÓRIA. PROCEDÊNCIA. EX-CÔNJUGE. CAPACIDADE LABORATIVA E APTIDÃO PARA INSERÇÃO NO MERCADO DE TRABALHO. RECURSO ESPECIAL. [...] 4. A jurisprudência desta egrégia Corte Superior firmou a orientação de que a pensão entre ex-cônjuges não está limitada somente à prova da alteração do binômio necessidade-possibilidade, devendo ser consideradas outras circunstâncias, como a capacidade potencial do alimentado para o trabalho e o tempo decorrido entre o início da prestação alimentícia e a data do pedido de desoneração. 5. Esta egrégia Corte Superior também tem entendimento de que, em regra, a pensão deve ser fixada com termo certo, assegurando ao beneficiário tempo hábil para que reingresse ou se recoloque no mercado de trabalho, possibilitando-lhe a manutenção pelos próprios meios. O pensionamento só deve ser perene em situações excepcionais, como de incapacidade laboral permanente, saúde fragilizada ou impossibilidade prática de inserção no mercado de trabalho. Precedentes. (REsp 1496948/SP, Rel. Ministro MOURA RIBEIRO, TERCEIRA TURMA, julgado em 03/03/2015, DJe 12/03/2015). No mesmo sentido, REsp 1353941/RJ, Dje 16/04/2013; REsp 1388116/SP, Dje 20/05/2014; REsp 1290313/AL, Dje 07/11/2013; REsp 1205408/RJ, Dje 29/06/2011.
} 
De acordo com o STJ, os alimentos em favor da ex-mulher devem ser limitados aos naturais, para evitar hipótese de enriquecimento sem causa e não fomentar o ócio. ${ }^{14}$ Novamente, o binômio necessidade e possibilidade é mitigado, ficando restrito tão somente ao primeiro elemento e de modo a se restringir à subsistência do ex-cônjuge, independentemente das condições financeiras do alimentante.

\section{Análise da culpa sobre o fim do casamento ou união estável}

Em que pese boa parte da doutrina afaste a noção de culpa pelo fim do casamento ou união estável, o fundamento legal previsto no art. 1.694, $\$ 2^{\circ}$ do Código Civil mantém aquele caráter punitivo bastante presente na jurisprudência.

A matéria da culpa e do cumprimento ou não dos deveres conjugais é objeto de análise dos Tribunais estaduais, de modo que a Súmula 7 do STJ impede a sua revisão. Em todo caso, é recorrente a menção sobre a culpa da alimentanda nos acórdãos. ${ }^{15}$

\section{A duração do casamento como requisito dos alimentos}

Embora ainda seja uma posição isolada como voto vencido em alguns acórdãos, cumpre mencionar o entendimento da Ministra Nancy Andrighi no sentido de que, além do vínculo conjugal, é necessária a convivência por longo período para a aplicação do dever de mútua assistência. ${ }^{16}$

${ }^{14}$ CIVIL E PROCESSO CIVIL. ALIMENTOS DEVIDOS AO EX-CÔNJUGE. PEDIDO DE EXONERAÇÃO. NEGATIVA DE PRESTAÇÃO JURISDICIONAL. INEXISTÊNCIA. VIOLAÇÃO DE DISPOSITIVO CONSTITUCIONAL. DESCABIMENTO. [...] 5. Os alimentos devidos entre ex-cônjuges não podem servir de fomento ao ócio ou ao enriquecimento sem causa. Por isso, quando fixados sem prazo determinado, a análise da pretensão do devedor de se exonerar da obrigação não se restringe à prova da alteração do binômio necessidade-possibilidade, mas deve agregar e ponderar outras circunstâncias, como a capacidade potencial do alimentado para o trabalho e o tempo decorrido entre o início da prestação alimentícia e a data do pedido de desoneração. 6. Particularmente, impõe-se a exoneração da obrigação alimentar tendo em vista que a alimentada está trabalhando, embora tenha afirmado que o valor recebido em contrapartida é insuficiente à própria manutenção, sendo, ademais, relevante o fato de que a obrigação de prestar alimentos, correspondentes a doze salários mínimos, subsiste há mais de dezoito anos, tempo esse suficiente e além do razoável para que ela pudesse se restabelecer e seguir a vida sem o apoio financeiro do excônjuge. [...] (REsp 1396957/PR, Rel. Ministra NANCY ANDRIGHI, TERCEIRA TURMA, julgado em 03/06/2014, DJe 20/06/2014). No mesmo sentido REsp 1112391/SP.

${ }^{15}$ CIVIL. SEPARAÇÃO. CULPA RECÍPROCA. PENSÃO ALIMENTÍCIA. Se reconhecida, na instância ordinária, culpa recíproca dos cônjuges, o marido não está obrigado a prestar alimentos. Recurso especial conhecido e provido. (REsp 306.060/MG, Rel. Ministro ARI PARGENDLER, TERCEIRA TURMA, julgado em 04/09/2001, DJ 29/10/2001, p. 204). Outros julgados que tratam da culpa: REsp 21.697/SP, julgado em 14/06/1993, DJ 27/09/1993, p. 19823 e REsp 1.025.769/MG, julgado em 24/08/2010, DJe 01/09/2010).

${ }^{16}$ Voto vencido: Não há a obrigação de ex-marido prestar alimentos à ex-mulher com base no dever de mútua assistência preconizado no artigo 1566, III, do CC de 2002 na hipótese em que o casamento durou apenas alguns meses, pois o período de duração do enlace matrimonial não foi suficiente ao menos para o conhecimento comum, o que esvaziou o dever de mútua assistência, que deriva da comunhão de vida e é construída ao longo do tempo, com a convivência do casal. Não há a obrigação de ex-marido prestar alimentos à ex-mulher na hipótese em que esta, apesar de ter interrompido sua carreira profissional durante os meses em que permaneceu casada, é pessoa jovem, que tem condições e formação profissional favoráveis à sua reinserção no mercado de trabalho, pois não está caracterizada a necessidade da alimentanda, um dos requisitos para a imp osição da obrigação de vol. 08, no. 04, Número Especial. Rio de Janeiro, 2015. pp. 2474-2492 


\section{A renúncia dos alimentos}

Entendimento bastante consolidado no STJ é o de que a renúncia aos alimentos é irreversível e independe da alteração do binômio possibilidade e necessidade. Eventual situação de miserabilidade posterior, ou mesmo as questões emocionais que envolvem o litígio do casal ao tempo da dissolução do casamento ou união estável, são ignoradas. ${ }^{17}$

Entretanto, essa renúncia aos alimentos só é definitiva em relação ao ex-marido enquanto este permanecer vivo. A Súmula $336^{18}$ e a jurisprudência do STJ ${ }^{19}$ admitem o direito à pensão previdenciária por morte se comprovada a necessidade econômica superveniente.

\section{ANÁLISE DA FUNDAMENTAÇÃO CONSTRUÍDA PELO SUPERIOR TRIBUNAL DE JUSTIÇA}

Os acórdãos trazidos à análise demonstram uma série de tendências, que se fundamentam a partir de elementos comuns. Assim, essas decisões, que em sua esmagadora maioria deferem pedidos de exoneração de alimentos, os quais haviam sido deferidos a ex-cônjuges mulheres, baseia-se nestes argumentos mais frequentes: a) a excepcionalidade do caráter dos alimentos a ex-cônjuge ${ }^{20}$; b) a necessidade de se estabelecer um lapso temporal

prestar alimentos. (REsp 1353941/RJ, Rel. Ministra NANCY ANDRIGHI, Rel. p/ Acórdão Ministro JOÃO OTÁVIO DE NORONHA, TERCEIRA TURMA, julgado em 16/04/2013, DJe 24/05/2013).

${ }^{17}$ ALIMENTOS. RENÚNCIA. DIVÓRCIO. É VÁLIDA E EFICAZ A CLÁUSULA DE RENÚNCIA A ALIMENTOS ("NÃO FICOU ESTABELECIDO QUALQUER CLAUSULA QUE OBRIGAVA O EX-MARIDO A PRESTAR ALIMENTOS A EXMULHER", SEGUNDO O ACORDÃO RECORRIDO), EM ACORDO DE SEPARAÇÃO. QUEM RENUNCIA, RENUNCIA PARA SEMPRE. O CASAMENTO VALIDO SE DISSOLVE PELO DIVORCIO. DISSOLVIDO O CASAMENTO, DESAPARECEM AS OBRIGAÇÕES ENTRE OS ENTÃO CONJUGES. A MÚTUA ASSISTENCIA E PROPRIA DO CASAMENTO. ILEGITIMIDADE DE PARTE ATIVA DA MULHER PARA A AÇÃO. RECURSO ESPECIAL NÃO CONHECIDO. (REsp 85.683/SP, Rel. Ministro NILSON NAVES, TERCEIRA TURMA, julgado em 28/05/1996, DJ 16/09/1996, p. 33740)

${ }^{18} \mathrm{~A}$ mulher que renunciou aos alimentos na separação judicial tem direito à pensão previdenciária por morte do ex-marido, comprovada a necessidade econômica superveniente. (Súmula 336, TERCEIRA SEÇÃO, julgado em 25/04/2007, DJ 07/05/2007, p. 456).

${ }^{19}$ PREVIDENCIÁRIO. PENSÃO POR MORTE. CÔNJUGE SEPARADO JUDICIALMENTE. RENÚNCIA ANTERIOR AOS ALIMENTOS. IRRELEVÂNCIA. 1. É devida a pensão por morte ao ex-cônjuge separado judicialmente, que comprove a dependência econômica superveniente, ainda que tenha dispensado temporariamente a percepção de alimentos quando da separação judicial. 2. Recurso não conhecido. (REsp 196.678/SP, Rel. Ministro EDSON VIDIGAL, QUINTA TURMA, julgado em 16/09/1999, DJ 04/10/1999, p. 91)

${ }^{20}$ Esse elemento pode ser encontrado nos seguintes acórdãos: STJ, REsp 1112391/SP, 3a T., Rel. Min. Nancy Andrighi, Rel. p/ Acórdão Min. Massami Uyeda, j. 07/04/2011, DJe 23/05/2011; STJ, REsp 1205408/RJ, 3a T., Rel. Min. Nancy Andrighi, j. 21/06/201 1, DJe 29/06/2011; STJ, REsp 1353941/RJ, 3a T., Rel. Min. Nancy Andrighi, Rel. p/ Acórdão Min. João Otávio de vol. 08, nº. 04, Número Especial. Rio de Janeiro, 2015. pp. 2474-2492 2480 
quando esses alimentos são arbitrados, com raras exceções apenas discursivamente consideradas ${ }^{21}$; c) o desestímulo ao ócio ou ao enriquecimento ilícito dessas mulheres ${ }^{22}$; d) a plena capacidade de reinserção no mercado de trabalho das mulheres envolvidas nos processos $^{23}$; e) a igualdade entre homens e mulheres em relação ao mercado de trabalho, e às suas possibilidades de inserção neste ${ }^{24}$.

O último desses elementos, a aludida igualdade de oportunidades de homens e mulheres em relação à inserção no mercado de trabalho, embora só seja evocado explicitamente em um julgado de $1993^{25}$, baliza todos os outros elementos: a excepcionalidade dos alimentos para ex-cônjuge e, portanto, a sua necessária temporalidade, tendo em vista a plena capacidade de reinserção no mercado de trabalho.

Ainda, a compreensão da prestação de alimentos como incentivo ao ócio só pode ser compreendida à luz de uma (suposta) sociedade na qual, enfim, homens e mulheres possuem igualdade, de forma que as mulheres são plenamente capazes de sustentar a si mesmas, e não necessitariam mais de qualquer auxilio de seus ex-maridos - o requerimento deste auxílio não pode ser, portanto, outra coisa senão ausência de vontade para o trabalho.

Essa parece ser a preocupação central dos (e da) Ministros(a), o que revela, a partir de uma dedução provável, que suas análises dos casos estão galgadas numa suposição comum acerca da realidade social: a de que as mulheres, uma vez conquistada dita igualdade no mercado de trabalho, e portanto tendo total capacidade de inserção neste espaço e de garantir o próprio sustento, ao requerer alimentos de ex-cônjuge, intencionam mais uma espécie de enriquecimento, do que a ideia mesma dos alimentos, qual seja, a de necessidade elementar e alimentar, para se viver de modo compatível com a sua condição social, conforme estabelece o caput do artigo 1.694 do Código Civil.

Em que pese esta pressuposição da igualdade entre homens e mulheres possa estar (aparentemente) ancorada na realidade, tendo em vista a igualdade entre o homem e a mulher prescrita pela Constituição Federal (art. $5^{\circ}$, inc. I), a crescente inserção das mulheres no mercado de trabalho ${ }^{26}$, como também o crescente aumento

Noronha, j. 16/04/2013, DJe 24/05/2013; STJ, REsp 1388116/SP, 3a T., Rel. min. Nancy Andrighi, j. 20/05/2014, DJe 30/05/2014; STJ, REsp 1396957/PR, Rel. Min. Nancy Andrighi, 3a T., j. 03/06/2014, DJe 20/06/2014; STJ, REsp 1496948/SP, 3a T., Rel. Min. Moura Ribeiro, j. 03/03/2015, DJe 12/03/2015.

${ }^{21}$ Esse elemento pode ser encontrado em todos os acórdãos acima, com acréscimo do seguinte: STJ, REsp 1290313/AL, 4ª T., Rel. Min. Antonio Carlos Ferreira, j. 12/11/2013, DJe 07/11/2014;

${ }^{22}$ Esse elemento está previsto em todos os acórdãos anteriormente citados.

${ }^{23}$ Esse elemento está previsto em todos os acórdãos anteriormente citados, com acréscimo do seguinte: STJ, REsp 21.697/SP, $4^{a}$ T., Rel. Min. Sálvio de Figueiredo Teixeira, j. 14/06/1993, DJ 27/09/1993.

${ }^{24}$ Esse elemento está previsto em todos os acórdãos anteriormente citados, ainda que em algum deles não seja explicitamente evocado.

${ }^{25}$ STJ, REsp 21.697/SP, 4a T., Rel. Min. Sálvio de Figueiredo Teixeira, j. 14/06/1993, DJ 27/09/1993.

${ }^{26}$ De acordo com o Instituto Brasileiro de Geografia e Estatística, a taxa de atividade das mulheres cresceu de 50,1 nos anos 2000 para 54,6 em 2010. INSTITUTO BRASILEIRO DE GEOGRAFIA E ESTATÍSTICA. Estatísticas de Gênero: uma análise do Censo Demográfico de 2010. Rio de Janeiro: 2014. P. 108. 
da formação dessas mulheres ${ }^{27}$, ainda assim uma busca mais atenta em relação ao estado da divisão do trabalho produtivo e reprodutivo por gênero permite uma visão crítica sobre as decisões.

De fato, publicações recentes no âmbito das pesquisas de gênero apontam que a divisão sexual do trabalho é ainda um elemento central na definição das limitações e possibilidades das mulheres no âmbito do trabalho remunerado, uma vez que seria o tempo do trabalho não remunerado, ou seja, do trabalho reprodutivo, que condicionaria as possibilidades de exercício do trabalho remunerado, ou seja, produtivo (BIROLI, 2014).

Do ponto de vista dos homens, percebe-se que o modelo de masculinidade hegemônica permanece marcado pelas posições de "responsável, provedor moral e material da família" (COUTO, 2013). É recente e ainda constante na vida cotidiana dos brasileiros, portanto, a identificação dos homens com o trabalho produtivo, e das mulheres com o trabalho reprodutivo (ÁVILA, 2013). Essa configuração mantém uma concepção naturalizante da responsabilidade das mulheres com o trabalho doméstico e de cuidado, o que leva a uma série de desvantagens sociais (BIROLI, 2014).

Nesse sentido, o Instituto de Pesquisa Econômica Aplicada apontou, em estudo publicado em 2011, que as mulheres economicamente ativas gastam cerca de 25 horas por semana com os afazeres domésticos, enquanto os homens economicamente ativos gastam apenas cerca de 10 horas com essas atividades. A pesquisa apontou, ainda, que o envolvimento dos homens no trabalho doméstico é inversamente proporcional ao número de filhos, de forma que quanto mais filhos, maior é o envolvimento feminino, e menor o masculino (IPEA, 2011).

Mas este dado precisa ser complementado com outro essencial: o fato de que o número de mulheres que abandonam o mercado de trabalho, mesmo com instrução, para priorizar o trabalho doméstico e o cuidado com os filhos, ainda é muito grande. O Instituto Brasileiro de Geografia e Estatística trouxe, assim, uma diferença de quase $20 \%$ na percentagem de população economicamente ativa entre homens e mulheres (74,6\% para os homens, e apenas $54,6 \%$ para as mulheres) (IBGE, 2014).

Compreender a diferença deduzida acima passa necessariamente por outro dado importante: o número de crianças que frequentam creches, e as mudanças no abandono ou permanência de suas mães em relação a esse número. De fato, enquanto o número de ocupação das mulheres com filhos de 0 a 3 anos de idade que frequentam creches é de 66,9\%, no caso da não frequência em creches, o número cai para 41,9\% (IBGE, 2014). Adicionando-se a esse dado um outro, que aponta que 77,5\% das mulheres com filhos de 0 a 3 anos convivem com o fato de que nenhum filho frequenta creche (BRASIL, 2014), pode-se ter um possível panorama da relação entre a não ocupação das mulheres e a necessidade de cuidado dos filhos.

\footnotetext{
${ }^{27}$ A mesma pesquisa acima demonstrou que 19,2\% das mulheres ocupadas possuem ensino superior, e $31 \%$ possuem ensino médio completo e superior incompleto, ao passo que dentre os homens ocupados as percentagens são $11,5 \%$ e $27,1 \%$, respectivamente. Ibid. P. 117.g
} 
Isso indica, de fato, que dentre as desvantagens da responsabilidade socialmente conferida às mulheres pelo trabalho doméstico e pelo cuidado estão "A interrupção da carreira, a opção por empregos de menor carga horária, porém mal remunerados e a mobilidade social negativa associada às duas primeiras" (BIROLI, 2014). Esses elementos fazem com que a mulher esteja constantemente exposta ao risco da pobreza e outras formas de vulnerabilidade, uma vez serem frequentes as relações de dependência econômica com o marido e/ou outros homens (BIROLI, 2014). Não por menos, constatou-se, em 2005, que as famílias mais abatidas pela miséria, no Brasil, são as monoparentais formadas pelas mães, sem cônjuges, e seus filhos (SORJ; GAMA, 2014).

Assim, em pesquisa de opinião desenvolvida pela Fundação Perseu Abramo e publicada no ano de 2013, dentre as razões que as mulheres que nunca trabalharam apontaram, estão "Filhos/Gravidez" com 28\%, "Trabalho Doméstico" com 22\% e "Casamento/Marido", com 21\% (BOKANY (coord.), 2013). Dentre as razões apontadas para terem parado de trabalhar, estão "Filhos/Gravidez" com 30\%, "Trabalho Doméstico" com 15\% e "Casamento/Marido" com 23\% (BOKANY (coord.), 2013).

A interpretação desses dados trazem o fato de que, de um lado, as mulheres ainda priorizam os cuidados e afazeres domésticos em relação ao trabalho remunerado, de forma que estancam ou mesmo param suas carreiras; de outro, a responsabilização exclusiva, ou ao menos predominante das mulheres pelo trabalho reprodutivo, é o que permite que os homens possam se dedicar amplamente seu tempo ao trabalho produtivo (BIROLI, 2014). Em suma, pode-se dizer ainda que:

Com efeito, o engajamento efetivo da força de trabalho feminina, quando determinada por pretensões de mobilidade social ascendente, vincula-se muito mais à concretização das possibilidades de ascensão dos membros masculinos da família que da própria mulher (SAFFIOTI, 2013).

Em um cotejo com os acórdãos analisados, percebe-se que, em muitos casos de exoneração de alimentos, a partir dos fundamentos elencados, tratam-se de mulheres com mais de 40 anos, que abandonaram ou estancaram suas carreiras em nome dos afazeres domésticos ou do cuidado dos filhos, de modo que o divórcio e o não recebimento dos alimentos pagos pelo ex-cônjuge levam a uma situação de mudança em suas condições econômicas, visto as dificuldades extras que essas mulheres têm de enfrentar por se verem na necessidade de retomar uma carreira após anos de formação, num contexto competitivo como o do mercado de trabalho contemporâneo ${ }^{28}$.

De fato, como exemplo paradigmático dessa situação, no REsp 1205408/RJ, que teve por Ministra Relatora Nancy Andrighi, a realidade econômica da alimentada foi trazida, e se constatou que esta, iniciada a sua tentativa de reinserção no mercado de trabalho, tinha rendimentos que variavam entre apenas 1 salário mínimo mensal e 3 salários mínimos mensais, numa situação na qual o ex-cônjuge lhe pagava alimentos no valor de cinco

\footnotetext{
${ }^{28}$ À guisa de exemplo, citem-se as seguintes decisões: STJ, REsp 1496948/SP, 3a T., Rel. Min. Moura Ribeiro, j. 03/03/2015, DJe 12/03/2015; STJ, REsp 1388116/SP, 3a T., Rel. min. Nancy Andrighi, j. 20/05/2014, DJe 30/05/2014.
} vol. 08, nº. 04, Número Especial. Rio de Janeiro, 2015.pp. 2474-2492 
salários mínimos mensais. Não obstante, o trabalho da alimentada serviu como argumento de constatação da possibilidade de exoneração dos alimentos ${ }^{29}$.

O que se constata, portanto, em relação às fundamentações das exonerações de alimentos de ex-cônjuge, é que estas se galgam na ideia de igualdade entre o homem e a mulher, a partir da errônea impressão passada pela mera igualdade jurídica. Torna-se necessário fazer a "distinção entre a igualdade jurídica (formal) e a igualdade material (igualdade efetiva no plano das relações sociais reais)" (HESPANHA, 2009). Essa divisão permite compreender a igualdade para além da igualdade legal, alcançando a igualdade substancial, que é caracterizada por tratar os diferentes a partir de sua diferença, buscando assim a materialização da igualdade constitucionalmente prevista.

Essa separação é importante, porque ressalta o risco de transformar a igualdade numa mera formalidade, que continua a ser afirmada e pressuposta como mito, enquanto nas relações reais as desigualdades continuam a ser reproduzidas. Um grande risco dessa postura, conforme identificado por Hespanha, é a desoneração da sociedade da responsabilidade por essa desigualdade, e a ilusão de que a responsabilidade por ela seria dos próprios desfavorecidos - no presente caso, as mulheres (HESPANHA, 2009).

Assim, vêem-se as dificuldades de reinserção no mercado de trabalho delas não como dificuldades reais, advindas das condicionantes que as mantiveram afastadas do mercado de trabalho, mas como problemas das próprias mulheres, que precisam ser incentivadas a buscar sua independência de seus ex-maridos, e afastadas do comodismo $^{30}$.

Percebe-se, portanto, que as decisões analisadas, muito ao contrário da aparente relação com as mudanças reais de igualdade entre homens e mulheres, permanecem reproduzindo desigualdades econômicas reais, a partir de um discurso de igualdade formal que, além de tudo, desconsidera a importância do trabalho doméstico realizado pelas mulheres como trabalho que possui valor.

No campo produtivo, há uma representação simbólica do trabalho de homens e do trabalho de mulheres e há uma divisão de tarefas que (cor)respondem a essa representação. Essa divisão incide também sobre o valor do trabalho de homem e mulher, expresso no valor diferenciado de salários e no desvalor do trabalho doméstico. Além disso, no trabalho produtivo há uma captura das habilidades desenvolvidas no trabalho doméstico (...) (ÁVILA, 2013).

O que Hespanha também aponta é que o direito não possui uma lógica unívoca, e que, portanto, é possível que haja decisões de ruptura, que apontem para a preocupação com a igualdade material (HESPANHA,

\footnotetext{
${ }^{29}$ STJ, REsp 1205408/RJ, 3a T., Rel. Min. Nancy Andrighi, j. 21/06/2011, DJe 29/06/2011.

${ }^{30} \mathrm{Tal}$ argumentação está presente nos seguintes acórdãos: STJ, REsp 1112391/SP, 3a T., Rel. Min. Nancy Andrighi, Rel. p/ Acórdão Min. Massami Uyeda, j. 07/04/2011, DJe 23/05/2011; STJ, REsp 1205408/RJ, 3a T., Rel. Min. Nancy Andrighi, j. 21/06/2011, DJe 29/06/2011; STJ, REsp 1388116/SP, 3a T., Rel. min. Nancy Andrighi, j. 20/05/2014, DJe 30/05/2014; STJ, REsp 1396957/PR, Rel. Min. Nancy Andrighi, 3a T., j. 03/06/2014, DJe 20/06/2014; STJ, REsp 1290313/AL, 4a T., Rel. Min. Antonio Carlos Ferreira, j. 12/11/2013, DJe 07/11/2014; STJ, REsp 1496948/SP, 3a T., Rel. Min. Moura Ribeiro, j. 03/03/2015, DJe 12/03/2015.
} 
2009). Isso abre a possibilidade para a reconfiguração do tratamento dos alimentos para ex-cônjuge, mas significa também que quando espaços de vulnerabilidade como este são produzidos pelo direito, outras alternativas jurídicas passam a ser pensadas para preenchê-los. É nesse sentido que os alimentos compensatórios acabam por se inserir nos processos aqui analisados.

\section{"ALIMENTOS COMPENSATÓRIOS" COMO POSSÍVEL EFEITO DA DESVALORIZAÇÃO DO INSTITUTO}

$\mathrm{Na}$ última década, paralelamente ao manejo cotidiano do clássico instituto dos alimentos, tanto pela doutrina, quanto pelos Tribunais pátrios, suscitou-se, entre os familiaristas brasileiros, a discussão acerca de uma nova figura jurídica, que passou a ser denominada de "alimentos compensatórios".

De plano, registre-se que o presente ensaio não tem por escopo adentrar à controvérsia que se instaurou na doutrina em torno dessa pretensa categoria jurídica, basicamente, por dois motivos: (i) o presente trabalho não tem por objeto a investigação acerca da viabilidade de se cogitar desse instituto no direito brasileiro; e (ii) tal discussão teve seu espaço circunscrito, em grande medida, à doutrina, mostrando-se infrutífera a tentativa de expôla, na medida em que o propósito, aqui, é proceder ao cotejo analítico das manifestações judiciais acerca do tema, notadamente do STJ.

De toda maneira, os chamados "alimentos compensatórios" repercutiram na experiência judiciária pátria recentemente, apesar de Rolf Madaleno reconhecer que a pensão compensatória não é estranha ao direito brasileiro (MADALENO, 2011), com base em um precedente datado de 1989, que possui a seguinte ementa:

ALIMENTOS. AÇÃO REVISIONAL. Peculiar natureza compensatória da pensão em prol da mulher, considerando que o vultoso patrimônio rentável tocou ao varão. Ação improcedente. Sentença confirmada. ${ }^{31}$

No Judiciáro, o tema ainda não encontrou contornos precisos. Isso porque há julgados em que os alimentos compensatórios serviriam para manter o equilíbrio econômico-financeiro entre os cônjuges, inclusive, do padrão de vida ${ }^{32}$; há julgados que consideram os alimentos compensatórios decorrentes da administração

\footnotetext{
${ }^{31}$ Apelação Cível No 588071712, Quinta Câmara Cível, Tribunal de Justiça do RS, Relator: Sérgio Pilla da Silva, Julgado em 04/04/1989. Disponível

em:

<http://www.tjrs.jus.br/busca/search?q=\&proxystylesheet=tjrs_index\&client=tjrs_index\&filter=0\&getfields=**aba=juris\&ents $\mathrm{p}=\mathrm{a} \_$_plitica-site $\& w c=200 \& w c \_m c=1 \& o e=U T F-8 \& i e=U T F-$

8\&ud=1\&lr=lang_pt\&sort=date\%3AD\%3AS\%3Ad $1 \&$ as_qj=\&site=ementario\&as_epq=\&as_oq=\&as_eq=\&partialfields=n\%3 A588071712\&as_q=+\#main_res_juris $>$.Acesso em 15.06.2015.

${ }^{32}$ DISTRITO FEDERAL. Tribunal de Justiça do Distrito Federal e Territórios. Agravo de Instrumento no 20090020030046 AGI. 6a Turma Cível. Relator Desembargador Jair Soares, j. 10/06/2009.
} 
exclusiva por um dos cônjuges dos bens comuns $^{33}$; há julgados que mesclam esses dois fundamentos ${ }^{34}$; há julgados que sustentam a natureza alimentar do instituto ${ }^{35}$; e há julgados que ressaltam a natureza indenizatória da verba $^{36}$.

Este cenário incerto, projetou-se, também, para o Superior Tribunal de Justiça. Aqui, apesar de o STJ não ter tratado diretamente do tema, senão apenas incidentalmente, cumpre expor três casos em que é possível se traçar o panorama geral do assunto nesta Corte.

A começar pela análise do acórdão prolatado pela 3a Turma do STJ, na sessão de 14 de maio de 2004, sob a relatoria do então Ministro Carlos Alberto Menezes Direito, em relação ao Habeas Corpus no 34.049/RS.

$\mathrm{Na}$ oportunidade, o remédio constitucional fora impetrado por um cidadão que alegava estar sofrendo constrangimento ilegal de sua liberdade de ir e vir por força da manifestação judicial que decretara sua prisão civil, em razão do inadimplemento de uma suposta verba alimentar, arbitrada com base no art. 4º parágrafo único, da Lei de Alimentos, que prevê a renda líquida dos bens comuns. O grande debate que se instaurou na Corte cingiuse à identificação da natureza da referida verba.

O relator, em seu voto, valendo-se da interpretação do próprio Tribunal de origem no julgamento dos embargos infringentes de que a verba não se tratava de alimentos, mas de uma antecipação da futura partilha em favor do cônjuge que não administrava os bens comuns, entendeu não ser possível a prisão civil neste caso ${ }^{37}$.

Seis anos depois, o STJ enfrentou uma vez mais a questão, também incidentalmente, no acórdão prolatado, novamente, pela 3a Turma, na sessão de $1^{\circ}$ de dezembro de 2011, sob a relatoria da Ministra Nancy Andrighi e redação do Ministro Massami Uyeda, em relação ao Recurso Ordinário em Habeas Corpus nº $28.853 /$ RS.

Neste caso, subjacente ao recurso, havia uma execução de alimentos, sob o rito da prisão civil, com base em título judicial exarado nos autos de separação judicial litigiosa, na qual se executavam valores arbitrados em favor do cônjuge mulher. A decisão que fixou a referida verba foi categórica em qualificá-la como "não alimentar", tendo em vista que se tratava de um repasse dos frutos oriundos do patrimônio do casal, que estavam sob a administração exclusiva. Apesar disso, ante o inadimplemento, o Juízo a quo decretou a prisão civil do devedor, declarando expressamente se tratar de uma obrigação alimentar, mesmo que de cunho compensatório, já que se destinava à mantença da autora.

${ }^{33}$ ESTADO DO RIO GRANDE DO SUL. Tribunal de Justiça do Rio Grande do Sul. Apelação Cível no 70026541623. Oitava Câmara Cível. Relator Desembargador Rui Portanova, j. em 04/06/2009.

${ }^{34}$ ESTADO DE SÃO PAULO. Tribunal de Justiça de São Paulo. Embargos de Declaração no 0024877-50.2007.8.26.0554. 6a Câmara de Direito Privado. Relator Desembargador Percival Nogueira, j. 03/12/2012.

${ }^{35}$ ESTADO DE SÃO PAULO. Tribunal de Justiça de São Paulo. Embargos de Declaração no 0024877-50.2007.8.26.0554. 6a Câmara de Direito Privado. Relator Desembargador Percival Nogueira, j. 03/12/2012.

${ }^{36}$ ESTADO DO RIO GRANDE DO SUL. Tribunal de Justiça do Rio Grande do Sul. Apelação Cível no 70061811212 . Oitava Câmara Cível. Relator Desembargador Rui Portanova, j. em 30/10/2014.

${ }^{37} \mathrm{E}$ tal entendimento se irradiou integralmente para os Tribunais inferiores, salvo em alguns casos como o do RHC no 28.853/RS. vol. 08, nº. 04, Número Especial. Rio de Janeiro, 2015.pp. 2474-2492 2486 
Em razão disso, impetrou-se habeas corpus perante o respectivo Tribunal, sendo denegada a ordem de soltura, por se entender que não havia ilegalidade na prisão.

Então, recorreu-se ao STJ, pois a ordem de prisão seria manifestamente ilegal e consistiria em um abuso de autoridade, já que o objeto da referida execução não teria natureza alimentar.

A Ministra Nancy Andrighi, relatora do caso, no item II de seu voto, considerando a tese de que a verba objeto de execução teria cunho compensatório, trata dos chamados alimentos compensatórios. Dessa manifestação, extrai-se as seguintes conclusões:

1. A Ministra utiliza a doutrina de Rolf MADALENO para delinear os contornos do tema;

2. Os alimentos compensatórios não se confundem com a renda líquida dos bens comuns, pois estes, à luz dos princípios da dignidade da pessoa humana e da solidariedade familiar, possuem "nítida natureza jurídica alimentar", sendo possível a prisão civil em caso de inadimplemento ${ }^{38}$;

3. A partilha é elemento essencial à concretização do desequilíbrio gerador das hipóteses da pensão compensatória; e

4. O entendimento da Corte, no caso do julgamento do HC 34.049/RS tratou de uma hipótese específica, que consistia em uma "verdadeira antecipação da futura partilha".

Com base nisso, negou-se provimento ao recurso.

Na sequência, o Ministro Massami Uyeda pediu vista dos autos, expondo, em seu voto, as seguintes ideias:

1. A prisão civil decretada pelo Juízo a quo seria manifestamente ilegal, eis que não havia pedido expresso da exequente para que a execução tramitasse pelo rito mais gravoso;

2. A verba executada não se revestiria de natureza alimentos, pois não decorreria do dever de solidariedade entre os cônjuges, mas sim do direito à meação, evitando-se o enriquecimento ilícito daquele que estivesse na posse dos bens comuns; e

3. Tal verba, ainda, não se confundiria com a denominada "pensão compensatória", apesar de serem próximas no que pertine à natureza ressarcitória de ambas.

Assim, conferiu-se provimento ao recurso.

Por fim, o Ministro Sidnei Beneti também pediu vista dos autos e, de seu voto, extraem-se as seguintes contribuições ao debate:

1. A expressão "alimentos compensatórios" é equívoca e gera confusões; e

${ }^{38}$ Nancy Andrighi cita, para tanto, o REsp 1.046.296/MG, DJe 8.6.2009. 
2. Sugere-se que o termo seja substituído por "prestação" ou "pensão compensatória", a exemplo das experiências francesa e espanhol, respectivamente, na medida em que sua natureza não é alimentar, mas indenizatória.

Em razão disso, entendeu-se pela inviabilidade da manutenção da prisão civil no caso em tela.

Recentemente, em novembro de 2013, o STJ voltou a enfrentar o tema, em um precedente de bastante repercussão na imprensa por se tratar de figura pública no cenário político nacional (RODRIGUES JUNIOR, 2014) ${ }^{39}$

Nesse caso, apreciado pela 4a Turma do STJ, na sessão de 12 de novembro de 2013, sob a relatoria do Ministro Antonio Carlos Ferreira, em sede de Recurso Especial interposto pelo ex-marido sob o argumento de julgamento extra petita pelo Tribunal de origem, teve com o seguinte suporte fático:

1. As partes, casadas desde 1984 pelo regime da separação convencional de bens, mantiveram a relação até 2005 , quando se separaram litigiosamente;

2. Na oportunidade, o marido ofertou alimentos no valor de $\mathrm{R} \$ 5.200,00$ (cinco mil e duzentos reais), proposta não aceita pela ex-consorte, que pretendia receber o montante de $\mathrm{R} \$ 40.000,00$ (quarenta mil reais);

3. Em sentença proferida pelo Juízo de $1^{\circ}$ grau, concedeu-se à ex-mulher dois automóveis e $\mathrm{R} \$ 900.000,00$ (novecentos mil) em imóveis, mais uma pensão na monta de trinta salários mínimos mensais, por tempo indeterminado;

4. O marido apelou ao TJ-AL, que minorou os alimentos para o montante de vinte salários mínimos pelo período de três anos, mantendo a sentença no restante; e

5. Em sede de embargos infringentes, restabeleceu-se a obrigação alimentar ao patamar dos trinta salários mínimos, afastando-se a limitação temporal de três anos.

Assim, admitiu a fixação de alimentos compensatórios para ex-cônjuge nos seguintes termos:

1. É possível a atribuição de alimentos compensatórios, na hipótese de quebra do equilíbrio econômicofinanceiro decorrente da separação;

2. Os alimentos devem ser fixados em prazo de três anos, a contar do trânsito em julgado da decisão;

3. Dever-se-ia admitir a transferência de bens de um cônjuge a outro.

No que pertine ao último ponto, divergiram os Ministros Antonio Carlos Ferreira e Marco Buzzi, entendendo este se tratar de uma violação ao pacto antenupcial.

\footnotetext{
39 RODRIGUES JUNIOR, Otávio Luiz. Alimentos compensatórios no Brasil e no exterior (parte 1). Disponível em: <http://www.conjur.com.br/2014-jan-08/direito-comparado-alimentos-compensatorios-brasil-exterior-parte>. Acesso em 15.06.2015.
} 
Em relação à limitação temporal de três anos, votaram a favor o Ministro Relator Antonio Carlos Ferreira e os Ministros Luís Felipe Salomão e Raúl Araújo. No sentido contrário, Marco Buzzi e Isabel Galotti sustentaram que seria difícil a colocação da ex-esposa no mercado de trabalho, pois dedicou grande parte de sua vida às atividades (políticas) do marido.

A partir da análise dos contornos fáticos e os fundamentos jurídicos envolvidos nos julgados que tratam de alimentos compensatórios vislumbra-se a (artificial) metamorfose de um direito existencial e da personalidade em obrigação de natureza estritamente patrimonial - como se as partes da relação jurídica fossem contratualmente iguais e a família que a deu origem fosse irrelevante.

Nesse contexto, em arremate ao presente ensaio, tentará se traçar um possível panorama jurisprudencial sobre o tema dos alimentos em favor da ex-esposa, a partir de problematizações críticas acerca da condição feminina no Brasil e sua projeção no Poder Judiciário.

\section{CONCLUSÃO}

Intencionar a reconstrução das compreensões de gênero constitui tarefa árdua. Com efeito, mesmo aquilo que melhor resiste às tramas androcêntricas, insurgente, nas subjetividades, enfrenta todo um contexto majoritariamente heteronormativo e binário, ainda que inconscientemente, a ensejar reflexão profunda, combativa e conjunta.

Elementos de tal realidade, as decisões judiciais, por mais técnicas que se apresentem - e, muitas vezes, declaradamente comprometidas com perspectivas emancipatórias -, dividem tempo e espaço com um enraizado senso comum de que remanesce, no significante feminino, reprimível tom de "golpismo", de "vigarismo", de "interesses financeiros escusos" a justificar afetos conjugais.

Se impossível mensurar quanto de tal compreensão efetivamente impacta, como pano de fundo tão nebuloso quanto a inconsciência, na ratio decidenci do Superior Tribunal de Justiça, é possível a seleção de temas especialmente sensíveis à condição feminina para se discutir a tendência dos julgadores.

Conforme se constatou, estreita-se, em sede jurisprudencial, a segurança alimentar às ex-esposas e às excompanheiras, aspecto sobre o qual remanescem argumentos fundamentando a decisão que não se confirmam com os dados nacionais e alguns aspectos do caso concreto. Em pretensa homenagem à igualdade entre os sujeitos da relação conjugal - a despeito da realidade vivida pelas mulheres brasileiras, que pouco se assemelha à letra constitucional formal -, os requisitos condicionantes para o estabelecimento de tal obrigação limitam, por óbvio, o alcance do instituto.

Quiçá em reação ao fenômeno, os alimentos compensatórios surgem com crescente força nos tribunais pátrios, remediando uma série de discrepâncias às quais a própria prática jurisdicional dá causa. Mesmo assim, 
raras são as associações entre tais movimentações e a apreensão dos papeis masculinos e femininos na sociedade brasileira hodierna.

Por tal motivo, remanesce o receio de que esta novidade possa significar pouco se não acompanhada da criteriosa problematização acerca do impacto que têm as questões de gênero na distribuição do poder econômico nas relações conjugais, mesmo que esta discussão cause desconforto ao jurista contemporâneo, que se pretende declarar, apenas pela força normativa, livre de fantasmas do passado, como a misoginia, a desvalorização do trabalho doméstico e o repúdio aos direitos humanos das mulheres.

A realização existencial e afetiva de uma pessoa é o especial e complexo campo de atuação do Direito das Famílias, por isso, ao nosso ver, há forte conexão com os Direitos Humanos, inclusive enquanto fundamento epistemológico - expressando os valores humanos fundamentais. Sob a luz da universalidade da temática, no campo internacional, a experiência histórica feminina brasileira deve estar presente como realidade social que não pode ser substituída por esteriótipos afastados da realidade concreta.

Almeja-se, portanto, uma jurisprudência nacional que não oprima nem suprima diferenças de gênero no campo dos alimentos e em outros tantos, ao passo que se milita por uma igualdade substancial. Como afirma Victor Hugo, "A primeira igualdade é a justiça."

\title{
SPOUSE SUPPORT IN FAVOR OF FORMER SPOUSE OR PARTER (ALIMONY AND PALIMONY): REFLECTIONS ON THE GENDER (IN)EQUALITY FROM THE JURISPRUDENCE OF THE BRAZILIAN SUPERIOR COURT OF JUSTICE
}

\begin{abstract}
This article aims to investigate the female status in the Judiciary, particularly in the Brazilian Superior Court of Justice, from the critical and analytical collation of the jurisprudence of this Superior Court in regard to Spousal Support awarded in favor of former spouse, wife or partner. It attempts to assert the ratio decidendi of judgments given in the period between the last biennium of the decade of 1980 to the present day, trying to elucidate the explicit or implicit, present or absent arguments in these decisions and their jut in the representation of women in Brazilian society.A strong inclination of this Court to temporally and quantitatively limit the alimony in favor of women is identified. As a rule, women's socioeconomic vulnerability, which originates from gender inequality within familiar environment, is neglected. Reimbursement Alimony is considered as a possible consequence of the devaluation of the legal category of spousal support. As a conclusion, the representation of women in Brazilian society is characterized by prejudice, which is also projected in the Judiciary.
\end{abstract}

Keywords: Female status. Gender inequality. Superior Court of Justice. Alimony (spousal support) devaluation. Reimbursement Alimony. 


\section{REFERÊNCIAS BIBLIOGRÁFICAS}

ÁVILA, Maria Betânia de Melo. A dinâmica do trabalho produtivo e reprodutivo: uma contradição viva no cotidiano das mulheres. In: Mulheres brasileiras e gênero nos espaços público e privado: uma década de mudanças na opinião pública. Org.: VENTURI, Gustavo; GODINHO, Tatau. São Paulo: Editora Fundação Perseu Abramo: Edições Sesc SP, 2013, p. 231-246.

BIROLI, Flávia. Famúlia: Novos Conceitos. São Paulo: Fundação Perseu Abramo, 2014. Justiça e Família. IN: MIGUEL, Luis Felipe; BIROLI, Flávia. Feminismo e Política. 1. ed. São Paulo: Boitempo, 2014.

BOKANY, Vilma (coord. op.); Núcleo de Opinião Pública da FPA. Mulheres Brasileiras e Gênero no Espaço Público Privado: Pesquisa Opinião Pública. In: Mulheres brasileiras e gênero nos espaços público e privado: uma década de mudanças na opinião pública. Org.: VENTURI, Gustavo; GODINHO, Tatau. São Paulo: Editora Fundação Perseu Abramo: Edições Sesc SP, 2013, p. 411-500.

BOURDIEU, Pierre. O poder simbólico. Lisboa: Difel, 1989.

BRASIL. Presidência da República. Secretaria de Políticas para as Mulheres. RASEAM: Relatóro Anual Socieconômico da Mulher - 2014.

COUTO, Márcia Thereza; SCHRAIBER, Lilia Blima. Machismo hoje no Brasil: uma análise de gênero das percepções dos homens e das mulheres. In: Mulheres brasileiras e gênero nos espaços público e privado: uma década de mudanças na opinião pública. Org.: VENTURI, Gustavo; GODINHO, Tatau. São Paulo: Editora Fundação Perseu Abramo: Edições Sesc SP, 2013, p. 47-62.

DIDUCK, Alison; O'DONEVAN, Katherine. Introduction: feminism and families plus ça change? In: Feminist perspectives on family law. Org.: Alison Diduck; Katherine O’Donevan. Abingdon: Routledge-Cavendish, 2006.

FACHIN, Luiz Edson. Um país sem jurisprudência. Revista IBDFAM, Edição 11, Maio 2014, p. 5.

GASTRON, Andrea; AMANTE, Maria Angela; RODRÍGUEZ, And Rubén. Gender arguments and gender perspectives in legal judgments in Argentina. In: Gender and judging. Org.: Ulrike Schultz; Gisela Shaw. Oxford: Oxford and Portland Oregon, 2013.

HESPANHA, António Manuel. Imbecillitas: as bem-aventuranças da inferioridade nas sociedades de Antigo Regime. São Paulo: Annablume, 2010.

O Caleidoscópio do Direito: O Direito e a Justiça nos dias e no mundo de hoje. 2. ed. Coimbra: Almedina, 2009.

INSTITUTO BRASILEIRO DE GEOGRAFIA E ESTATÍSTICA. Estatísticas de Gênero: uma análise do Censo Demográfico de 2010. Rio de Janeiro: 2014.

INSTITUTO DE PESQUISA ECONÔMICA APLICADA. Retrato das desigualdades de gênero e raça. Brasília: IPEA, 201 1, p. 37.

MADALENO, Rolf. Curso de Direito de Família. 3.ed. Rio de Janeiro: Editora Forense, 2011. 
OLIVEIRA, Rosa Maria Rodrigues de. "Isto é contra a natureza...": acórdãos judiciais e entrevistas com magistrados sobre conjugalidades homoeróticas em quatro estados brasileiros. In: Conjugalidades, parentalidades e identidades lésbicas, gays e travestis. Org.: GROSSI, Miriam; UZIEL, Anna Paula; MELLO, Luiz. Rio de Janeiro: Garamond, 2007.

RODRIGUES JUNIOR, Otávio Luiz. Alimentos compensatórios no Brasil e no exterior (parte 1). Disponível em: $\quad<$ http://www.conjur.com.br/2014-jan-08/direito-comparado-alimentos-compensatorios-brasil-exteriorparte>. Acesso em 15.06.2015.

SAFFIOTI, Heleith Iara Bongiovani. A mulher na sociedade de classes: mito e realidade. 3. ed. São Paulo: Expressão Popular, 2013.

SORJ, Bila; GAMA, Andrea. Family policies in Brazil. In: Handbook of family policies around the globe. Ed. Mihaela Robila. New York: Springer, 2014.

Trabalho enviado em 11 de setembro de 2015.

Aceito em 07 de outubro de 2015. 